Uludag Univ. J. Fac. Vet. Med.

33 (2014), 1,2: 43-48

\title{
Subklinik Laminitis ile İlgili Araştırmalar
}

\author{
Göksen ÇEÇEN
}

Geliş Tarihi: 29.09.2014

Kabul Tarihi: 15.10 .2014

Özet: Tüm dünyada kabul edildiği üzere, topallıklar sığırlar için ciddi bir refah sorunudur. Sığır topallıklarının şekillenmesinde laminitis'in subklinik formunun önemli bir rol oynadığı kabul edilir. Hastalığın bu formu yaygın olup, teşhisi ise oldukça güçtür. Hayvanların bireysel olarak sağaltımları pratik olmadığı için, sürü genelinde hastalığa karşı gerekli tedbirler alınmalıdır.

Anahtar Kelimeler: Subklinik laminitis.

\section{Researches on Subclinical Laminitis}

\begin{abstract}
As it is accepted all over the world, lameness in cattle are serious welfare problem. Subclinical laminitis is considered to play an important role in the development of lameness in cattle. This form of the laminitis is very widespread but the diagnosis is very difficult. Treatment of animal is impractical as an individual therefore it is necessary measures should be taken in all herd.
\end{abstract}

Key Words: Subclinical laminitis.

\section{Giriş}

Laminitis sadece tırnakları değil, sığırların genel durumunu da etkileyen önemli bir sistemik hastalıktır. Sı ğırlarda laminitisin patogenezisi üzerinde hala çeşitli spekülasyonların varlığına rağmen, temel prensipler büyük oranda belirlenmiştir. Araştırmalar hastalığın multifaktöriyel olduğunu göstermektedir. Aslında problemin ciddiyeti, klinik belirtileri dikkati çekmeyen "subklinik" formun, çeşitli tırnak lezyonları oluşumunda predispoze bir faktör olmasından kaynaklanmaktadır. Subklinik form, hastalığın erken aşamalarında patofizyolojik bir takım değişikler şekillenmesine rağmen, klinik olarak herhangi bir bulgunun oluşmadığı süreci ifade etmektedir.

Bu derlemede, subklinik laminitis'in insidans1, etiyoloji ve patogenezisi, bulguları, tan1- sal değerlendirmeleri ve hastalığın önlenmesine ilişkin bilgilerin, araştırmalar ışığında sunulması amaçlanmıştır.

\section{İnsidans}

Sığırlarda laminitis ile ilgili kapsamlı ve sistematik ilk araştırma, 1963 yilında Nilson tarafindan yapılmıştır. 1976 yılına kadar hastalığın yalnızca akut, subakut ve kronik formları biliniyorken, sonraları Toussaint-Raven tarafindan "subklinik" formun varlığı ortaya çıkarılmıştır ${ }^{(14)}$. Tüm dünyada son 20 yıllık süreçte, sığırlarda tırnak lezyonlarının etiyolojisinde subklinik laminitis'in önemli bir faktör olabileceği tartışılmış ve tabanda ülserler, beyaz çizgide ayrılma, çift taban oluşumu, ökçelerde ve tırnak dokusunda değişen derecelerde büyüme ve deformasyonların nedeni olarak görülmüştür $3,5,14,16,18,24,25,30,32$.

\footnotetext{
1 U.Ü. Veteriner Fakültesi, Cerrahi Anabilim Dalı, Bursa / TÜRKIYE, goksenc@uludag.edu.tr
} 
Sürülerde olası topallık insidans $\%$ 0-60 arasında bildirilmiştir ${ }^{14}$. Topallık büyük ekonomik kayıplara yol açmasına rağmen, yetiştiriciler topallığın yaygınlığı ve şiddetini çoğunlukla olduğundan daha düşük tahmin etmektedir ${ }^{29}$. Bununla birlikte, özellikle klinik belirtileri dikkati çekmeyen subklinik laminitis ile ilişkili ne kadarlık bir kayba uğradığının farkında olmamaktadır $^{7}$. Weaver ${ }^{32}$, topallığa neden olan ayak hastalıklarının \%50'sinin laminitisle ilgili olabileceğini ileri sürmektedir. Araştırmalar, ülkemizde de sorunun önemini koruduğu ve y1llar içerisinde artış gösterdiğini (\%7-58) belgelemektedir ${ }^{2,3,8,9,13,26-28,33}$. Çeçen ve ark. ${ }^{10}$, klinik olarak sağlıklı sığır tırnakları üzerinde yaptıkları histopatolojik incelemelerde, subklinik laminitis oranını \%43 olarak saptamışlardır. Ayak ve tırnak yapısında bazı değişiklikler şekillendiği halde klinik belirti göstermeyen subklinik laminitis olgularının tespitinin zorluğu dikkate alınırsa, laminitisin gerçek insidansının belirlenmesinin oldukça güç olduğu anlaşılmaktadir ${ }^{10,16,25}$

\section{Etiyoloji ve Patogenez}

Subklinik laminitis, düşük dereceli etkenlerin sürekli olarak etkimesi ile oluşan, uzun süreli ve yavaş gelişen bir olaydır. Tabandaki hemoraji, sarı renk değişikleri ve yaygın yumuşama bunun bir göstergesi olup, sürü problemi şeklinde karşımıza çıkabilir. Bu bulgular, düvelerde \% 50-60 oranında görülebilirr ${ }^{19,23}$. Sistemik hastalıklar, yaş ve gebelik, laktasyon dönemi, konformasyon ve genetik gibi bireysel faktörler; beslenme, bakım ve barınma, egzersiz düzeyi, çevre ve davranış gibi sürü düzeyinde etkili faktörler sığırlarda histamin, laktik asit ve endotoksinler ile kortikosteroid, progesteron ve östrojen gibi hormonların kan seviyelerinin değișmesine neden olur. Tane yemler ile aşırı beslenme, sığırların soğuğa maruz kalması, midebarsak yangıları nedeni ile sindirim sistemi mukozasının kan-histamin düzeyinin normal sınırlarda kalmasını sağlayacak bariyer görevini yapamaması gibi nedenler ile histaminin patojenik etkilerine olan duyarlılığı artırır. Histamin vazodilatasyona sebep olur. Vazodilatasyon ise konjesyon, kan akımında azalma ve durgunluk hipoksisine yol açar. Rumen asidozisi neticesinde açığa çıkan endotoksinlerde ayağın canlı dokusunda kalıc1 hasara neden olan mikrovaskülar bozukluklara neden olur ${ }^{1,4-7,14-16,19,24}$.

Genel olarak kabul edilen, salınan sistemik mediatörlerin, tırnağın koryum'unda bulu- nan kan damarlarındaki karmaşık patolojik yanıtı tetiklediği yönündedir ${ }^{18,24}$. Laminitis'in subklinik formu, muraltrombozis ile sonuçlanır ve bu durum arteriyosklerozise neden olur. $\mathrm{Bu}$ değişiklik, pododermal hemodinamik değişiklikleri etkileyebilir ve sonuçta damarsal bütünlük kaybı, tabanda hemoraji, zayıf kaliteli tırnak dokusu oluşumu ve dorsal duvar konkavitesine yol açar ${ }^{20}$.

\section{Bulgular}

Subklinik laminitisli hayvanlarda klinik olarak duruș ve yürüyüș bozukluğu yoktur. Tabandaki hemoraji, sarı renk değişikleri ve yaygın yumuşama hastalığın bir göstergesi olarak yorumlanır (Şekil 1). Bu bozukluklar, daha sonra tabanda ülserler, beyaz çizgide ayrılma, çift taban oluşumu, ökçelerde ve tırnak dokusunda değişen derecelerde büyüme ve deformasyona neden olur (Şekil 2). Burada tırnak deformasyonlarının tekrarlayan laminitis nöbetleri sonucu ortaya çıktığı kanısı hakimdir ${ }^{3,14,16,19,24,25}$.

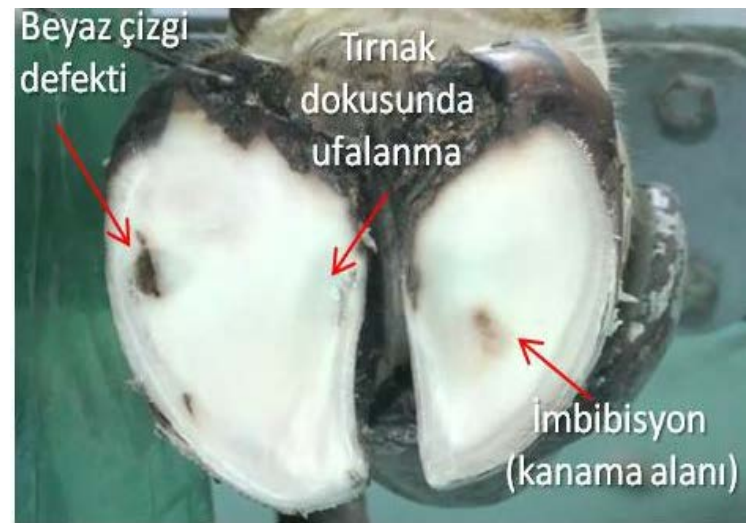

Şekil 1. Subklinik laminitis'te tırnak tabanında gözlenen bulgular (Çeçen G.)

Fig. 1. The clinical signs of subclinical laminitis in bovine sole horn (Cecen $G$.)

Subklinik laminitisin göstergesi olabilecek makroskopik bulgularla, ön ayaklarda ve lateral tırnaklarda daha fazla karşılaşılmaktadır. Bu durum subklinik laminitisin etiyolojisindeki travmatik faktörler ile ve arka ayak tırnaklarındaki suspensor dokunun, ön ayak tırnaklarına göre daha güçlü olmasının bir sonucu olarak laminitisten daha az oranda etkilenmiş olmalarına bağlanabilir ${ }^{10,11}$.

Bazı araştırma sonuçları, sığır tırnağında morfolojik yapıda meydana gelen bu değișiklikler ile subklinik laminitis varlığ $\breve{g a s i n d a}_{1}$ her zaman çok güvenilir bir ilişki olmadığını da göstermektedir $^{8-10}$. 


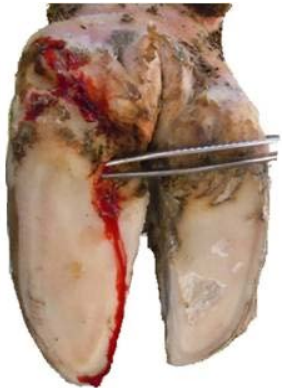

a. Tabanda ülser

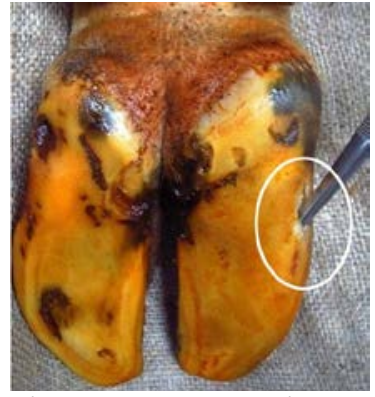

b. Beyaz çizgi ayrılması

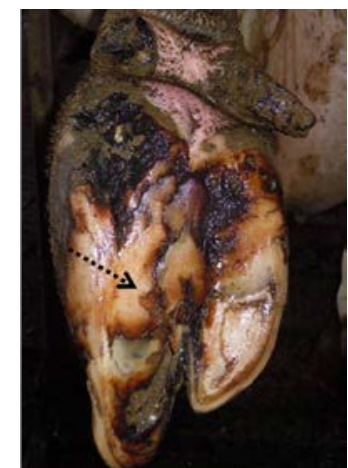

c. Çift taban oluşumu, tırnak dokusunda düzensiz büyüme

\section{Şekil 2. Subklinik laminitis ile ilişkili gelişen} lezyonlar (Çeçen G.)

Fig. 2. The lesions associated with subclinical laminitis (Cecen G.)

a. Ulcus solea

b. White line separations

c. Double sole horn and irregular growth of horn tissue

\section{Tanı}

Subklinik olguların kaçırılmaması için tüm tırnakların ayrıntılı muayenesi önem taş1maktadır. Subklinik laminitis varlığında deneyimler ve makroskopik bulguların yorumlanmas1 ayaktaki tüm değişiklikleri karakterize etmek için yeterli gibi gözükse de, bu bulguları kesin olarak doğrulayabilmek için histopatolojik muayene gerekir ${ }^{8}$. Saha koşullarında hastalığın tespitine yönelik yapılabilecek muayeneler s1nırlı kalmaktadır. Yapılan çalışmalarda, 3. falanks ile tırnak ön duvarı ve taban arasındaki mesafenin radyolojik ve ultrasonografik değerlendirme sonuçlarının, atlarda ve eşeklerde (sub)klinik laminitisin tespitinde yararlı olduğu belirtilmektedir ${ }^{22,31}$. Literatürde, laminitisli tırnak kapsulası fiziksel olarak yumuşak ve su içeriği belirgin oranda daha yüksek olduğu için ultrasonografik muayene ile birçok patolojik bulgunun değerlendirilebileceği kaydedilmiş- $\operatorname{tir}^{17}$. Çeçen ve ark. ${ }^{10}$, subklinik laminitisin sürü bazında tanısının ultrasonografik muayene ve ölçümlerle mümkün olmadığını bildirmişlerdir. Radyografik muayeneler ise, laminitisin ancak dinamik sürecinde değerli bilgiler sağlayabilmektedir ${ }^{12,21}$.

Tırnak kapsulasında görülen değişim ve lezyonlar, koryum'da meydana gelen patolojik değişimleri yansıtır. Bazı vakalarda klinik ile post mortem bulgular önemli derecede korelasyon göstermekle birlikte, bazı renk değişikliklerini tamamıyla normal tırnaklarda karşılaşılan düzensiz konjesyon nedeni ile oluşmuş kırmızı lekelerden ayırmak zordur ${ }^{23,24}$. İyi klinik kayıtları yardımı ile dikkatli bir şekilde yapılan post mortem muayene ve bulguların yorumlanması ayak hastalıklarının yapısı ve oluşumu üzerine önemli bilgiler sağlayacaktır.

Literatürde subklinik laminitisin ilk ya da ikinci fazının erken safhasında koryum duvarında ve özellikle kompresyon altındaki tabanda yaygın kanamalar oluştuğu bildirilmektedir ${ }^{6,24}$. Çeçen ve ark. ${ }^{10}$, subklinik laminitise bağlı olarak kapsula ve koryumda şekillenen kanamaların ön ayaklarda ve lateral tırnaklarda daha fazla görüldüğünü ve bunların daha çok fokal kanamalar şeklinde olduğunu bildirmişlerdir (Şekil 3).

Histopatolojik muayene, kapsula ve koryumda meydana gelen patolojik değişimleri doğrulamak için yardımcıdır. Subklinik laminitisli tırnakların histopatolojik muayenesinde; dermal-epidermal lamella arasındaki bağlantıda azalma ve kayıplar, epidermal lamellalarda uzama, incelme, uçlarında sivrilme (Şekil $4 b$ ), bazal membranda ayrılma, bazal hücrelerde morfolojik değişiklikler, bazal hücrelerde kromatin yoğunluğunda değişim, suprabazal hücre katmanında artış (Şekil 4d), doku nekrozu ve dermal lamellada yangı bulguları (hiperemi, ödem, hemoraji, trombotik emboli, lökosit infiltrasyonu) görülür (Şekil 4c) ${ }^{10,18,19}$. Laminitis tanısı konulmasında tırnak duvarı ve taban bölgeleri tanıda daha belirleyicidir. Ökçe dokusu histolojisi itibariyle lamellar epitel yerine çok katlı yassı epitel ile kaplı olduğundan tek başına laminitis yönünden histopatolojik değerlendirilmeyip tırnak duvarı ve taban ile birlikte bir bütün olarak ele alınmalıdır ${ }^{10}$. 


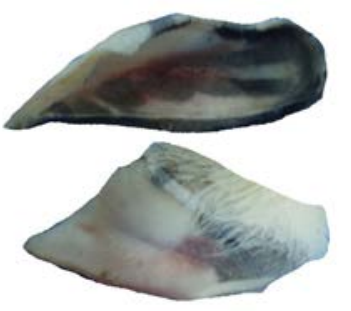

\section{a. Normal kapsula ve} koryum

(Olgu 53- SaÖL)

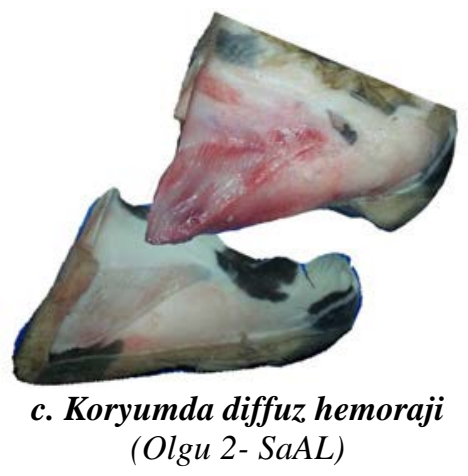

Şekil 3. Subklinik laminitisli olgularda $(b, c)$ kapsula ve koryumda kanama alanlarl $(S a \ddot{O L}=$ Să̆ ön ayak, lateral tırnak; SoAM=Sol arka ayak, medial tırnak; SaAL=Săg arka ayak, lateral tırnak) (Çeçen ve ark. ${ }^{10}$ ).

Fig. 3. The hemorrhagic area at capsula and corium in cases of subclinical laminitis $(b, c)$. (SaÖL = The lateral claw of right front foot; SoAM = The medial claw of left hind foot; $S a A L=$ The lateral claw of right hind foot) (Cecen et all ${ }^{10}$ ).

a. The normal capsula and corium (Case 53- SaÖL)

b. The focal hemorrhage at capsula and corium (Case 20-SoAM)

c. The diffuse hemorrhage at corium (Case 2$S a A L)$

\section{Profilaksi}

Subklinik laminitis’e neden olmamak için laktasyonun farklı dönemlerinde ineğin vücudunda gerçekleşen fizyolojik ve metabolik değişimi dikkate alacak bir beslenme programı uygulanmalidır. Rumende normal fermentasyonun oluşabilmesi için, rumen $\mathrm{pH}$ değeri optimal sınırlar içinde (pH 5,8-6,2) olmalıdır. Son yıllarda, rumen sindirimi üzerinde olumlu etkileri nedeniyle, probiyotik (bakteri, mantar ve maya), prebiyotik (sindirilmeyen kompleks karbonhidrat olan oligosakkaritler) ve enzim gibi alternatif yem katkı maddeleri de kullanılmaktadır. Maya ve mantarlar, rumende laktik asit düzeyini düşürür. Laktik asit düzeyinin düşmesi, rumende $\mathrm{pH}^{\prime} \mathrm{y}$ artırır ve stabilite sağlar. Ayrica maya ve mantarlar rumendeki oksijeni tüketerek, anaerobik ortamın sürdürülmesini sağlarlar. Böylece rumen $\mathrm{pH}$ 'sının korunması sağlanmış olur. Bunun dışında metabolik hastal1klar, stress ve travmalar gibi risk faktörleri engellenmelidir. Hayvanların doğumdan önceki aylarda ve doğumdan hemen sonraki dönemde, egzersiz amaçlı yürümelerini sağlayacak koşullar oluşturulmalı ve yaşamları süresince düzenli ayak bakımları yapılmalıdır. Uygun barınak koşullarında sığırlarda yatış süresinin uzaması subklinik laminitis kontrolünde anahtar nokta$\mathrm{dir}^{9,14-16}$.

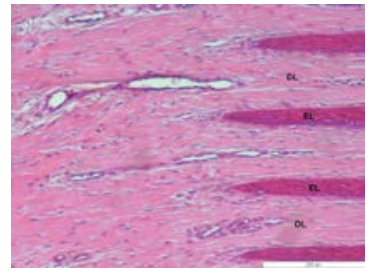

(a) x100'lük büyütme

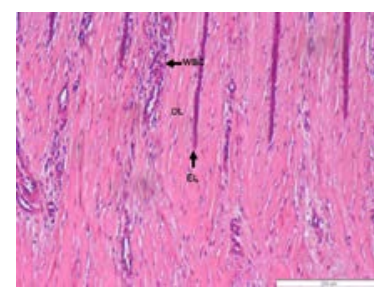

(c) x100’lük büyütme

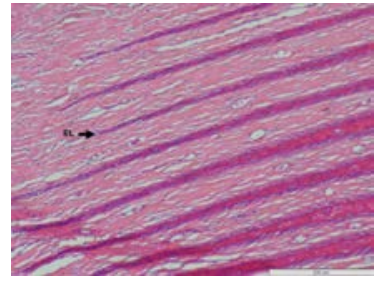

(b) x100'lük büyütme

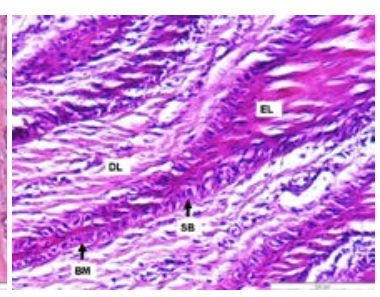

(d) x200'lük büyütme
Şekil 4. Sağllklı (a) ve laminitis olarak değerlendirilen bazı olgularda $(\boldsymbol{b}, \boldsymbol{c}, \boldsymbol{d})$ laminar kesit-

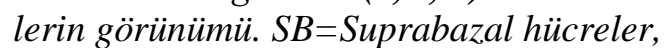
$B M=$ Bazal membran, $D L=$ Dermal lamella, $E L=$ Epidermal lamella, $W B C=$ Yangı hücreleri (dokuya infiltre olmuş lökositler) (Çeçen ve ark. $^{10}$ ).

Fig. 4. The view of laminar sections in cases of healthy (a) and laminitic ( $b, c, d$ ). $S B=$ Suprabasal cells, $B M=$ Basal membrane,

$D L=$ Dermal lamellae, $E L=$ Epidermal lamellae, $W B C=$ Inflammatory cells (tissue-infiltrating leukocytes) (Cecen et all ${ }^{(10)}$ ).

\section{Sonuç}

Sığır yetiştiriciliğinde önemli bir problem olan laminitisin subklinik formu, oldukça yaygın, teşhisi güç ve birçok ayak hastalığı için predispoze bir faktördür. Sürülerde latent seyreden bu durumun neden olacağı sonuçları önle- 
mek için, sürü yönetimi, çevre ve beslenme uygulamaları dikkatle yapılmalıdır.

\section{Kaynaklar}

1. Andersson L., Bergman A., 1980. Pathology of Bovine Laminitis especially as regards Vascular Lesions. Acta Veterinaria Scandinavica, 21, 559566.

2. Atasoy N., 2003. Erzurum Yöresinde Süt Sığırlarında Görülen Ayak Hastalıklarının İnsidansı ve Bunların Sağaltımı, YYÜ. Vet. Fak. Derg. 2003, 14 (1):1-5.

3. Belge A., Bakir B., Gönenci R., Ormanci S., 2005. Subclinical laminitis in dairy cattle: 205 selected cases. Turk. J. Vet. Anim. Sci., 29: 9-15.

4. Bergsten C., Frank B., 1996. Sole haemorrhages in tied heifers in early gestation as an indicator of laminitis: effects of diet and flooring, Acta Veterinaria Scandinavica, 37, 375-381.

5. Bergsten C., 2003. Causes, risk factors, and prevention of laminitis and related claw lesions, Acta Veterinaria Scandinavica, Suppl., 98, 157-166.

6. Berry L.S., 2001. The three phases of bovine laminitis, Hoof Trimmers Association Inc.'s Newsletter,

http://www.dairylandhoofcare.com/Articles/New

-Articles/3\%

20Phases\%20Bovine\%20Laminitis\%203.pdf

7. Blowey R., 1993. Cattle Lameness and Hoofcare, In: Farming Press, Ipswich, UK pp: 3-21.

8. Canpolat İ., Bulut S., 2003. Elazı̆̆ ve çevresinde sığırlarda görülen ayak hastalıklarının insidansı üzerine gözlemler, F.Ü. Sağllk Bil. Dergisi, 17(3), 155-160.

9. Çeçen G., Görgül O.S., 2007. Bursa Yöresindeki Bir İșletmede, Sağmal Süt Sı ğırı Sürüsünde Karş1laşılan Topallıkların Değerlendirilmesi, Veteriner Cerrahi Dergisi, 13 (1), 5-10.

10. Çeçen G., Seyrek İntaş D., Çelimli N., Misırlıoğlu D., Nisbet H.Ö., Salcı H., Alasonyalılar Demirer A., Çalışkan (Kabakaya) G.Ü., Görgül O.S., 2011. Normal ve Laminitis'li Sığır Tırnaklarında Capsula ve Corium Ungulae'nin Morfolojik Özelliklerinin Radyolojik, Ultrasonografik ve Postmortem Olarak Değerlendirilmesi, TÜBİTAK Projesi (1070817).

11. Danscher A.M., Toelboell T.H., Wattle O., 2010. Biomechanics and histology of bovine claw suspensory tissue in early acute laminitis., Journal of Dairy Science, 93, 53-62.

12. Gantke S.M., Nuss K., Kostlin R.G., 1998. Radiographic findings in laminitic claws, 10th International Symposium on Lameness in Ruminants, Lucerne-Switzerland, pp 155-156.
13. Görgül O.S., 1988. Sığırlarda Tırnak Bakımı ve Ayak Hastalıkları Sebep ve Sonuç İlişkileri, $U$. Ü. Vet. Fak. Derg., 7 (1,2,3): 34-37.

14. Greenough P.R., 2007. Bovine Laminitis and Lameness. A hands-on approach, Saunders \& Elsevier, Toronto.

15. Greenough P.R., Vermunt J.J., 1991. Evaluation of subclinical laminitis in a dairy herd and observations on associated nutritional and management factors, Veterinary Record, 128, 11-17.

16. İzci C., 1994. Sığırların Önemli Bir Ayak Hastalı̆̆ı; Laminitis (Derleme), Lalahan Hay. Arş. Ens. Der. 34 (1-2) 25-37.

17. Kofler J., Kubber P., Henninger W., 1999. Ultrasonographic imaging and thickness measurement of the sole horn and underlying soft tissue layer in bovine claws, The Veterinary Journal, 157, 322-331.

18. Lischer C.J., Ossent P., 2002. Pathogenesis of sole lesions attributed to laminitis in cattle. Proceedings of the 12th International Symposium on Lameness in Ruminants, Orlando, Florida, January 9-13, 82-89.

19. Mulling K.W., Lischer C.J., 2002. New aspects on aetiology and pathogenesis of laminitis in cattle. Ed: Kanske M., Scholz H., Holtershinken M., Proceedings of the 22nd World Buiatrics Congress, Hannover, Germany, Pp 236-258.

20. Nocek J.E., 1997. Bovine Asidosis: Implications on Laminitis. Journal of Dairy Science, 80, 10051028.

21. Nuss K., Köstlin R.G., Gantke S., Fuhrmann U., 1997. Radiology of laminitis in cattle., European College of Veterinary Surgeons Sixth Annual Scientific Meeting, Scientific Presentation Abstracts, June 27 - 29, Pp 258, Versailles, France.

22. Olivier-Carstens A., 2004. Ultrasonography of the solar aspect of the distal phalanx in the horse. Vet. Radiol. Ultrasound., 45:449.

23. Ossent P., Lischer C., 1998. Bovine laminitis: the lesions and their pathogenesis. In Practice, 20(8), 415-427.

24. Ossent P., Lischer C., 1997. Post mortem examination of the hooves of cattle, horses, pigs and small ruminants under practice conditions. In Practice, 19, 1, 21-28.

25. Özsoy, S., 1997. Sütçü sığırlarda subklinik laminitis, Veteriner Cerrahi Dergisi, 3 (2), 87-90.

26. Saglıyan, A., Ünsaldı, E., 2002. Tunceli ve yöresindeki sıgırlarda görülen ayak hastalıklarının insidansı üzerine gözlemler. F.Ü. Saglik Bilimleri Dergisi, 16 (1),47-56.

27. Seyrek-İntaş, D., Gül N.Y., Çeçen G., Kanık S., Sağlık Y., Tan H., Salcı H., Çelimli N. ve Görgül O.S., 2001. Bursa Yöresinde Sığırlarda Karşılaş1lan Ayak Hastalıkların Değerlendirilmesi: 249 olgu (1996-2001), II. Ulusal Buiatri Kongresi 
(Uluslar Arası Katılımlı), (sözlü tebliğ), 65-66, Bursa.

28. Şındak, N., Keskin, O.: Selçukbiricik, H., Sertkaya, H., 2003. Şanlıurfa ve Yöresinde Sığır Ayak Hastalıklarının Prevalansı, YYÜ. Veteriner Fakültesi Dergisi 14 (1): 14-18.

29. Socha, M.T., Tomlinson, D.J., Rapp, C.J., Johnson, A.B., 2002. Lameness: Diagnosis and Impact on Reproduction., Hoof Health Conf., Columbus, Ohio, USA. pp.16-19.

30. Vermunt JJ., 1992. Subclinical Laminitis in Dairy Cattle, $N$ Z Vet J., 40(4):133-138.

31. Walker M., Taylor T., Slater M., Hood D., Weir V., Elslander J., 1995. Radiographic appearance of the feet of Mammoth donkeys and the finding of subclinical laminitis, Veterinary Radiology \& Ultrasound, 36(1), 32-37.

32. Weaver A.D., 1998. Subclinical laminitis (Workshop report), 10th International Symposium on Lameness in Ruminants, LucerneSwitzerland, pp 148.

33. Yayla S., Aksoy Ö., Kılıç E., Cihan M., Özaydın İ., Ermutlu C.Ş., 2012. Kars ve yöresinde sığırların bakım ve barındırma koşulları ile ayak hastalıkları arasındaki ilişkinin değerlendirilmesi, Harran Üniv. Vet. Fak. Derg. 1(1): 22-27. 